Relations industrielles

Industrial Relations

\title{
L'automatisation du travail de bureau : problèmes administratifs et humains, W.H. Scott, Publications de l'O.C.D.E., Paris, France. 1965, 116 pages.
}

\section{Ronald Pleau}

Volume 21, numéro 1, 1966

URI : https://id.erudit.org/iderudit/027658ar

DOI : https://doi.org/10.7202/027658ar

Aller au sommaire du numéro

Éditeur(s)

Département des relations industrielles de l'Université Laval

ISSN

0034-379X (imprimé)

1703-8138 (numérique)

Découvrir la revue

Citer ce compte rendu

Pleau, R. (1966). Compte rendu de [L'automatisation du travail de bureau : problèmes administratifs et humains, W.H. Scott, Publications de l'O.C.D.E., Paris, France. 1965, 116 pages.] Relations industrielles / Industrial Relations, 21(1), 107-107. https://doi.org/10.7202/027658ar

Tous droits réservés (C) Département des relations industrielles de l'Université Laval, 1966
Ce document est protégé par la loi sur le droit d'auteur. L’utilisation des services d’Érudit (y compris la reproduction) est assujettie à sa politique d'utilisation que vous pouvez consulter en ligne.

https://apropos.erudit.org/fr/usagers/politique-dutilisation/ 
ditions qui réduisent la mobilité et accroissent la dépendance vis-à-vis l'organisation; 3) ces systèmes semblent se retrouver dans tous les genres d'organisations: entreprise privée, syndicalisme, religion, etc . . .

Pour vérifier ces hypothèses, l'auteur s'appuie sur une étude empirique auprès de 800 firmes. Deux chapitres sont consacrés à la présentation et analyse des données: I'un s'applique aux organisations hors du monde des affaires, l'autre s'applique au monde des affaires.

Dans le quotrième chapitre, l'outeur tente d'expliquer l'existence de ces systèmes, oprès avoir fait une synthèse des données sur la grandeur des entreprises, la mobilité des membres et l'ubiguité des systèmes d'appels. II trouve alors certaines explications à ceux-ci : (1) un produit dérivé du syndicalisme, (2) un résultat de l'humanisme industriel qui influence le management et (3) une conséquence du processus de la bureaucratisation.

Enfin, dons un dernier chapitre, l'auteur explique l'esprit dans lequel sont administrés ces systèmes: autocratique, législatique ou démocratique. Ces trois formes sont définies et les ovantages et désavantages en sont soulignés. De fait, on constate alors la nécessité d'un système démocratique dans les organisations si l'on ne veut pas créer des inégalités dangereuses entre les personnes de l'organisation. Et Scott suggère: * If the organization cannot be democratized, in the literal meaning of the word, it can at least be constitutionalized $\boldsymbol{~}$. (p. 125).

\section{Fernand Blais}

L'automatisation du travail de bureau : problèmes administratifs et humains, $W$. $H$. Scott, Publications de I'O.C.D.E., Paris, France. 1965. 116 pages.

Autre sujet d'actualité que celui de l'automation. Mais cette fois il s'agit d'un type d'automation relativement récent et qui prend depuis quelques années une expansion de plus en plus considérable.

Le travail de bureau est d'une nature différente de celui de d'autres secteurs d'activités et l'automation des travaux administratifs pose des problèmes qui sont aussi d'une nature particulière.

Parmi ces problèmes se posent ceux relatifs à une politique de main-d'oeuvre ayant trait aux relations industrielles. Personne ne doute que lorsqu'il survient des changements tels que ceux qui résultent de l'automation, le personnel se trouve grandement affecté. Aussi le but de ce rapport est d'aider à comprendre les exigences imposées aux entreprises et aux postes de travail et permettre d'établir des politiques et des programmes en vue de réduire au minimum les problèmes administratifs et humains imposés aux travailleurs par I'introduction des ordinateurs dans le travail de bureau. L'expérience de quatre pays européens, ainsi que "les lacunes et besoins constatés en matières de politiques et de programmes, et les efforts nécessaires pour faire accepter cet équipement nouveau » sont exposés dans cette étude.

Les transformations qui surviennent se situent surtout au niveau des structures de salaire, de la ligne de promotion, des conditions physiques de travail et de la composition de la main-d'oeuvre.

On constatera de plus que là où la maind'oeurre est syndiquée, il y a possibilités de négociation et de consultation pour celleci ce qui réduit d'autant la gravité des problèmes posés. Ceci aura " une incidence sur les réactions du personnel et sur le degré d'acception ou d'opposition que les changements rencontreront .

C'est donc par l'étude des rapports présentés par une entreprise du Royaume-Uni, d'une banque française, des compagnies d'assurances de la Suède et l'industrie en Allemagne qu'on réussira à mieux comprendre et connaître les tensions, l'apathie et la méfiance que posent les changements technologiques dans le domaine du travail clérical, à comprendre également comment une réduction de la main-d'oeuvre peut se faire sans heurt dans ces circonstances et l'incidence que peuvent avoir ces transformations sur les cadres de la direction et sur les employés.

Certes on peut très facilement après lecture d'un tel ouvrage proclamer son utilité mais il ne faut pas oublier que l'on traite d'un processus en voie d'évolution et que ses applications les plus poussées appartiennent encore à l'avenir.

\section{Ronald Pleau}

\section{Consentement ou Refus - Les travailleurs} et les changements techniques, par Alain Touraine et ses collaborateurs, O.C.D.E., Paris. 1965.135 pages.

Afin d'adapter au mieux le changement technique aux attentes et oux aspirations 